\title{
Supply Chain Contracts in Fashion Department Stores: Coordination and Risk Analysis
}

\author{
Bin Shen, ${ }^{1}$ Pui-Sze Chow, ${ }^{2,3}$ and Tsan-Ming $\mathrm{Choi}^{3}$ \\ ${ }^{1}$ School of Glorious Sun of Business and Management, Donghua University, Shanghai 200051, China \\ ${ }^{2}$ Department of Decision Sciences, School of Business, Macau University of Science and Technology, Wai Long Avenue, Taipa, Macau \\ ${ }^{3}$ Business Division, Institute of Textiles and Clothing, The Hong Kong Polytechnic University, Hung Hom, Kowloon, Hong Kong
}

Correspondence should be addressed to Pui-Sze Chow; lpschow@outlook.com

Received 2 May 2014; Accepted 11 July 2014; Published 6 August 2014

Academic Editor: Xiaohang Yue

Copyright (C) 2014 Bin Shen et al. This is an open access article distributed under the Creative Commons Attribution License, which permits unrestricted use, distribution, and reproduction in any medium, provided the original work is properly cited.

\begin{abstract}
In the fashion industry, department stores normally trade with suppliers of national brands by markdown contract whilst developing private labels with cooperated designers by profit sharing contract. Motivated by this real industrial practice, we study a singlesupplier single-retailer two-echelon fashion supply chain selling a short-life fashion product of either a national brand or a private label. The supplier refers to the national/designer brand owner and the retailer refers to the department store. We investigate the supply chain coordination issue and examine the supply chain agents' performances under the mentioned two contracts. We find the analytical evidence that there is a similar relative risk performance but different absolute risk performances between the national brand and the private label. This finding provides an important implication in strategic interaction for the risk-averse department stores in product assortment and brand management. Furthermore, we explore the impact of sales effort on the supply chain system and find that the supply chain is able to achieve coordination if and only if the supplier (i.e., the national brand or the private label) is willing to share the cost of the sales effort.
\end{abstract}

\section{Introduction}

Consumers love to buy fashion-related products in department stores because of their decent environment and a variety of product lines. Some well-known department stores include Selfridage.co and Harrods in UK, Macy's, J. C. Penney, and Saks Fifth Avenue in USA, and Lane Crawford in Hong Kong. It is common for these fashion department stores to sell national brands. For instance, all major fashion department stores in New York City trade with national brands such as Tommy Hilfiger by the markdown (MD) contract [1]. Under the MD contract, the department store pays a wholesale price to the national brand for procurement. In the middle of selling season, the national brand will grant a certain amount of money to support the department store for markdown. We call this supportive money as the markdown price. On the other hand, department stores also cooperate with individual well-established designers to develop private labels by the profit sharing (PS) contract [2]. Under the PS contract, the designer is responsible for the design of the products of the private label whilst the department store is responsible for both production and sale in the supply chain. The gross profit is shared between the two parties, which is agreed before the selling season starts. In other words, production cost is incurred and sales revenue is collected by the same party, whereas the gross profit is distributed to both parties at the end of the selling season as agreed [3]. A well-known illustration of such in the fashion industry is the top news story about Liz Claiborne selling exclusively by J. C. Penney from 2010 fall under a 10-year licensing deal. Specifically, Liz Claiborne is responsible for design whilst J. C. Penney organizes sourcing, production, marketing, and distribution. In return, Liz Claiborne shares a portion of the gross profit as the design service fee and royalties [2].

Nowadays in USA it is common for national fashion brands like Tommy Hilfiger and Polo Ralph Lauren to distribute their products through various department stores under the MD contract, while more and more fashion brands, 
such as Liz Claiborne, Disney, Dockers, and Carter's, have reformed to offer exclusive brands to be sold in department stores under the PS contract [4]. Motivated by these industrial practices, the objectives of this paper are to address the following questions.

(1) Which is a better strategy for the department store with profit and risk consideration: to sell a national brand or develop a private label?

(2) How can supply chain coordination be achieved between the department store and the national brand/private label?

(3) How does sales effort affect supply chain coordination between the department store and the national brand/the private label?

To achieve the objectives above, we study a two-echelon fashion supply chain with a retailer (department store) and a supplier selling a short-life fashion product under the MD or PS contract, when the supplier is a national brand or a private label, respectively. We first study the structural properties of the supply chain in both decentralized and centralized settings under the MD and the PS contracts and derive the respective analytical conditions for supply chain coordination and compare the corresponding performance of individual agents under the two contracts. Then we investigate how sales effort affects contract performance and supply chain coordination. Some main findings are as follows. First, there is a similar relative risk but different absolute risks for individual supply chain agents under the two contracts when supply chain coordination is achieved. Second, by exploring the impact of sales effort on the supply chain, we find that supply chain can be coordinated if and only if the supplier is willing to share the cost of sales effort. To the best of our knowledge, it is the first study to investigate and compare supply chain performance with the national brand and the private label in fashion department stores. Being two of the most popular supply chain contracts in the fashion industry, the analytical models of the MD and the PS contracts are driven by the industrial practice and our findings provide useful managerial insights that are highly applicable to the fashion industry.

This paper is structured as follows. In the next section, we summarize the related literature. Section 3 provides the details of our model and then the analytical results are derived. Section 4 discusses the impact of sales effort on supply chain. We conclude this paper with discussion in Section 5. All proofs are relegated to the Appendix.

\section{Literature Review}

Over the past decades, a considerable amount of research works have been devoted to supply chain contracts and supply chain coordination (for a comprehensive review of supply chain contracts, please refer to Cachon [5]). The benefits for coordinating supply chain contracts are their ability in enhancing the supply chain's performance by dampening the double marginalization effect and in allowing a proper share of risk and profit between the buyer and the supplier.
It is well-known that, under a two-echelon single-supplier single-retailer fashion supply chain with a newsvendor type of fashionable product, many of the above supply chain contracts can achieve supply chain coordination.

In this paper, we focus on examining $\mathrm{MD}$ and $\mathrm{PS}$ contracts. MD contract has been intensively explored in the field of fashion supply chain management. Hausman and Thorbeck [7] study the MD contract on fast fashion. They indicate that the MD contract can lead to a significant percentage increase in the profits for all supply chain parties. Ning et al. [8] study the effect of e-marketplace on supply chain under the MD contract and analytically find that the higher the demand in e-marketplace, the lower unit markdown allowance. Lately, the achievability of supply chain coordination under the MD contract is also discussed. Wang and Webster [9] take the fashion apparel industry as background and show that the MD contract can coordinate supply chain. Further, Shen et al. [10] analytically establish the conditions for achieving supply chain coordination when the fashion supply chain with a downstream risk-neutral retailer and an upstream risk-averse supplier. They employ real data collected from the fashion industry and develop interesting insights related to the profit's coefficient of variation of the supply chain.

The study of the PS contract is popular in the supply chain management literature but few of them are under the context of fashion supply chains. Jeuland and Shugan [11] are amongst the first in the literature to propose the use of the PS contract to achieve supply chain coordination. They consider that the manufacturer receives not only a fraction of the chain-wide profit, but also a fixed amount; thus the retailer receives the rest of the chain-wide profit minus the fixed amount. They find that the PS contract can help supply chain to achieve channel coordination and profit maximization. Jaber and Osman [12] investigate a twoechelon supply chain with consideration of permissible delay in payments for achieving supply chain coordination. They find that the PS contract is able to generate net savings among the players in the supply chain. Leng and Parlar [13] examine the game-theoretic models of lead-time reduction in a two-echelon supply chain with the PS contract. They find that the PS is easy to implement for achieving supply chain coordination. Wei and Choi [3] examine a wholesale pricing and profit sharing scheme for coordinating supply chain under the mean-variance approach. They find that the retailer can be benefited by pretending to be more risk averse in the information asymmetric case.

Despite their popularities in the literature concerning channel coordination, the MD and the PS contracts are rarely compared directly. Tsay [14] studies the MD contract and return policy. In fact, the MD contract is similar to the returns/buyback policy $[5,15,16]$, but the former does not require the physical return of the leftover products. On the other hand, based on Cachon and Lariviere [17], the buyback policy is equivalent to the revenue sharing contract. However, the revenue sharing contract is different from the PS contract. Specifically, under the latter supply chain agents share both the production cost and the revenue whereas the former splits the revenue only. Our comparison 
TABLE 1: The expression of the EP and SP for all parties under the PS and MD contracts.

\begin{tabular}{lccc}
\hline & Contract & $\mathrm{EP}$ & $\mathrm{SP}$ \\
\hline \multirow{2}{*}{ Retailer } & $\mathrm{PS}$ & $\mathrm{EP}_{\mathrm{R} \_\mathrm{PS}}(q)=\phi[(r-c) q-(r-v) n(q)]$. & $\mathrm{SP}_{\mathrm{R} \_\mathrm{PS}}(q)=\phi(r-v) \sqrt{\xi(q) .}$ \\
& $\mathrm{MD}$ & $\operatorname{EP}_{\mathrm{R} \_\mathrm{MD}}(q)=(r-w) q-(r-m-v) n(q)$. & $\mathrm{SP}_{\mathrm{R} \_\mathrm{MD}}(q)=(r-m-v) \sqrt{\xi(q) .}$ \\
\hline \multirow{2}{*}{ Supplier } & $\mathrm{PS}$ & $\mathrm{EP}_{\mathrm{S}_{-} \mathrm{PS}}(q)=(1-\phi)[(r-c) q-(r-v) n(q)]$. & $\mathrm{SP}_{\mathrm{S}_{-} \mathrm{PS}}(q)=(1-\phi)(r-v) \sqrt{\xi(q)}$. \\
& $\mathrm{MD}$ & $\mathrm{EP}_{\mathrm{S} \_\mathrm{MD}}(q)=(w-c) q-m n(q)$. & $\mathrm{SP}_{\mathrm{S} \_\mathrm{MD}}(q)=m \sqrt{\xi(q) .}$ \\
\hline
\end{tabular}

Notes. $n(q)=\int_{0}^{q} F(x) d x$ and $\xi(q)=2 q \int_{0}^{q} F(x) d x-2 \int_{0}^{q} x F(x) d x-\left(\int_{0}^{q} F(x) d x\right)^{2}\left(\xi^{\prime}(q) \geq 0\right.$ (please refer to Choi et al. for details) [6].

between the MD and the PS contracts is significantly different from the previous research in supply chain contracts. We believe that this paper is the first piece of research work that compares the two contracts with the consideration of both channel coordination and risk. More importantly, our study is motivated by the real practices in the fashion industry and the results are highly applicable to the operations of fashion department stores.

Lately, various researchers consider sales effort in the analytical studies of supply chain management [18-20]. For instance, Taylor [18] and Chiu et al. [20] investigate the use of sales effort in achieving an implementable win-win situation for channel coordination under sales rebate contract. Krishan et al. [21] show that a buyback policy alone cannot coordinate the channel; however, coupling buybacks with promotional cost-sharing agreements does result in coordination. Gurnani and Erkoc [19] study three different contracts with manufacturer-quality and retailer effort-induced demand in which both product quality and sales effort are positively influencing demand but incur the corresponding costs. They show that the price-only contract is dominated by the general franchise menu contract. In this paper, we also examine the impact of sales effort on individual agents' profits and risk and compare the performances between the PS and the MD contracts with sales effort consideration.

\section{The Model}

We consider a two-echelon fashion supply chain with a single retailer (department store) and a single supplier selling a newsvendor type of fashion product to consumers. The supplier is either a private label or a national brand. In order to be comparable, we consider that the cost-revenue parameters for products by both the national brand and the private label are the same. Specifically, the unit retail price is $r$, the unit production cost is $c$, and the unit salvage value of the product is $v$.

We consider the supplier as the Stackelberg leader who first offers the contract (MD contract when the supplier is the national brand, and PS contract when it is the private label). Being the follower, the retailer (the department store) then places an order based on the contract offered. For the national brand, the MD contract includes the wholesale price $w$ and the markdown price $m$. For the private label, the PS contract includes the profit sharing portion by the retailer $\phi$. In other words, the two parties make a joint effort in business and after sales season, the retailer keeps a portion $\phi$ of the gross profit that the joint venture business generates, and the supplier shares the remaining portion, $(1-\phi)$, of the gross profit. To avoid trivial cases, we consider $0 \leq \phi<1$ and $r>w>\max (m, c) \geq \min (m, c)>v$ hereafter in this paper. Market demand is randomly distributed and all unsatisfied demands are lost at the end of the season. Market demand is denoted by a random variable $x$ with a probability density function (p.d.f.) $f(x)$, and a corresponding cumulative density function (c.d.f.) $F(x)$ defined over the continuous interval $[0, \infty)$. There exists a one-to-one mapping between $F(x)$ and its argument $x$. Denote the inverse function of $F(x)$ by $F^{-1}(x)$.

We use the following abbreviations throughout this paper: $\mathrm{EP}=$ expected profit, $\mathrm{SP}=$ standard deviation of profit. In addition, we use the subscripts of " $S, R$, and SC" to denote "supplier, retailer, and supply chain," respectively.

Table 1 depicts the EP and SP for the whole supply chain, the supplier, and the retailer under the MD and PS contracts, respectively. Note that the expected profit of the supply chain is given by the sum of its agents' expected profits: $\mathrm{EP}_{\mathrm{SC}}=$ $\mathrm{EP}_{\mathrm{R}}+\mathrm{EP}_{\mathrm{S}}$.

For supply chain coordination, we follow the usual norm and define that the goal of supply chain coordination is to achieve

$$
q_{\mathrm{R} \_l}^{*}=q_{\mathrm{SC}}^{*}=F^{-1}\left[\frac{(r-c)}{(r-v)}\right], \quad \text { where } l \in[\mathrm{MD}, \mathrm{PS}]
$$

In the following subsections, we derive the analytical conditions under which supply chain channel coordination can be achieved under the PS and the MD contracts, which represent the two different observed industrial cases in fashion department stores.

3.1. Coordination under the PS Contract. Checking the first and second order derivatives of $\operatorname{EP}_{\mathrm{R}_{\_} \mathrm{PS}}(q)$ and $\mathrm{EP}_{\mathrm{SC}_{2} \mathrm{PS}}(q)$, we have retailer's and supply chain's optimal ordering quantity as follows, respectively:

$$
q_{\mathrm{R} \_\mathrm{PS}}^{*}=q_{\mathrm{SC}}^{*}=F^{-1}\left[\frac{(r-c)}{(r-v)}\right] \text {. }
$$

Lemma 1. Under the PS contract, (i) the retailer's optimal ordering quantities are independent of the profit sharing portion $\phi$, and (ii) the supply chain is always coordinated.

The PS contract helps the supply chain agents to integrate. All agents' self-interests (in terms of EP) are consistent with 
the centralized supply chain when adopting the PS contract. As an agreement on how the profit is split, $\phi$ is an indicator to reflect the power of the supply chain agents. Specifically, a retailer with higher supply chain power takes a higher $\phi$. According to Lemma 1(i), it is interesting that $q_{\mathrm{R} \_\mathrm{PS}}^{*}$ are independent of $\phi$. In other words, under the PS contract, supply chain power between the parties would not affect the ordering quantity and feasibility of channel coordination.

Next, we define by $\Delta_{i}$ the coefficient of variation $(\mathrm{CV})$ of profit for the supply chain agent $i$ as follows:

$$
\frac{\mathrm{SP}_{i}(q)}{\mathrm{EP}_{i}(q)}=\Delta_{i}, \quad i \in\{\mathrm{R}, \mathrm{S}, \mathrm{SC}\} .
$$

Here $\Delta_{i}$ measures party $i$ 's profit uncertainty. Notice that $\mathrm{CV}$ is a relative measure which indicates the level of risk per each unit of expected profit. We argue that it is meaningful to use $\mathrm{CV}$ as an analytical measure to evaluate the relative risk of the entire supply chain and its agents. Note that Cachon [22] and Shen et al. [10] both indicate that a lower value of $\mathrm{CV}$ means a better performance for the supply chain. Observe that both SP and CV are measures of risk in supply chain risk analysis [10,23]. A larger SP implies a higher absolute risk and a larger CV implies a higher relative risk (with respect to the expected profit).

Proposition 2. Under the PS contract, (i) both EP and SP of the retailer are increasing in $\phi$, but both EP and SP of the supplier are decreasing in $\phi$; (ii) $\Delta_{S_{-} P S}, \Delta_{R P S}$, and $\Delta_{S C \perp P S}$ are independent of $\phi$.

Proposition 2(i) states that EP and SP for both supply chain agents depend on $\phi$. Therefore, other than being a decision variable to determine the sharing of the supply chain profit between agents, $\phi$ also affects the variability of an agent's profit in the supply chain system.

Counterintuitively, Proposition 2(ii) shows that CV of both supply chain agents is independent of $\phi$. The result can partially be explained by the fact that ordering quantities are the same under the decentralized and centralized supply chains with the use of the PS contract. More interestingly, this result implies that if the retailer (supplier) takes a low (high) $\phi$, it does not necessarily mean its relative risk is low. Instead it does not need to worry about its supply chain performance in terms of the relative risk because $\phi$ would not affect the CV.

3.2. Coordination under the MD Contract. By checking the first order derivative of $\operatorname{EP}_{\mathrm{R}_{-} \mathrm{MD}}(q)$, we have the retailer's optimal ordering quantity which maximizes its expected profit as follows:

$$
q_{\mathrm{R} \_\mathrm{MD}}^{*}(m, w)=F^{-1}\left[\frac{(r-w)}{(r-m-v)}\right] .
$$

With the same logic, the supply chain's optimal quantity which maximizes $\mathrm{EP}_{\mathrm{SC} \_\mathrm{MD}}(q)$ is shown below:

$$
q_{\mathrm{SC} \_\mathrm{MD}}^{*}(m, w)=F^{-1}\left[\frac{(r-c)}{(r-v)}\right] .
$$

Similar to the existing literature in supply chain coordination (e.g., $[6,10])$, to achieve coordination under the MD contract, the contract parameters must satisfy the following condition:

$$
\frac{(r-w)}{(r-m-v)}=\frac{(r-c)}{(r-v)} .
$$

Proposition 3. Let $m^{*}$ and $w^{*}$ satisfy (5). Define $K=w-m$. Then, under a coordinating MD contract,

(i) $E P_{S}\left(q_{R \_M D}^{*}\left(m^{*}, w^{*}\right)\right)$ is decreasing in $m^{*}$ and $E P_{R}\left(q_{R \_M D}^{*}\left(m^{*}, w^{*}\right)\right)$ is increasing in $m^{*}$;

(ii) $K^{*}$ is decreasing in $w^{*}$ and $m^{*}$.

From Proposition 3(i), a higher $m^{*}$ implies a greater retailer's profit and a smaller supplier's profit. In this aspect, the optimal markdown price (i.e., $m^{*}$ ) can be treated as an indicator of profit allocation between the two agents under supply chain coordination. In turn, it can also reflect the supply chain power of the two agents within the supply chain [14]. For example, a relatively low optimal markdown price suggests that the supplier might have a higher degree of bargaining power within the supply chain as it can obtain a larger share of the supply chain profit.

By definition, $K$ is the difference between the wholesale price $(w)$ and the markdown price $(m)$. It measures the unit revenue loss for the supplier due to compensation to the retailer for unsold items under the MD contract. A higher $K$ may also reflect that the retailer is afraid of losing its revenue. From Proposition 3(ii), it is interesting to note that, under a coordinating $\mathrm{MD}$ contract, increasing either the optimal wholesale price or the optimal markdown price can lower the optimal revenue loss $K^{*}$ of the supplier.

3.3. Comparison between the MD and the PS Contracts. For a notational purpose, let $q_{\mathrm{SC} l}^{*}$ be the optimal retailer's order quantity under coordinating $l$ contract in the decentralized settings. Specifically, $q_{\mathrm{S} C \_\mathrm{PS}}^{*}=q_{\mathrm{SC}}^{*}, q_{\mathrm{S} C \_\mathrm{MD}}^{*}=q_{\mathrm{R} \_\mathrm{MD}}^{*}\left(m^{*}, w^{*}\right)$. As a remark, $q_{\mathrm{SC} \_\mathrm{PS}}^{*}=q_{\mathrm{SC} \_\mathrm{MD}}^{*}=q_{\mathrm{SC}}^{*}$.

Next, we conduct a comparative analysis between the MD and the PS contracts. The insights are shown below.

Proposition 4. (i) When $m \leq[(w-c)(r-v)] /(r-c)$, one has $q_{R \_P S}^{*} \geq q_{R \_M D}^{*}$. $q_{R \_M D}^{*}$

(ii) When $m>[(w-c)(r-v)] /(r-c)$, one has $q_{R_{-} P S}^{*}<$

In the decentralized setting, the retailer's optimal ordering quantity is influenced by the contract parameters when trading with the supplier under the MD contract. Proposition 4 shows that if the markdown price is sufficiently high (low), the retailer would order more (less) under the MD contract than under the PS contract.

Proposition 5. Under the coordinating PS and MD contracts:

(i) when $m \geq(1-\phi)(r-v)$, both EP and SP of the retailer under the PS contract are higher than those under the $M D$ contract; otherwise, both EP and SP of the retailer under the PS contract are lower than those under the $M D$ contract; 
TABLE 2: The expression of the EP and SP for all parties under the PS and MD contracts with sales effort consideration.

\begin{tabular}{|c|c|c|}
\hline & & Expected profit \\
\hline \multirow{2}{*}{ Retailer } & PS & $\mathrm{EP}_{\mathrm{R}_{-} \mathrm{CP}}(Q, e)=e \phi[(r-c) Q-(r-v) n(Q)]-\lambda \beta e^{2}$ \\
\hline & MD & $\mathrm{EP}_{\mathrm{R}_{-} \mathrm{NB}}(Q, e)=e[(r-w) Q-(r-m-v) n(Q)]-\lambda \beta e^{2}$ \\
\hline \multirow{2}{*}{ Supplier } & PS & $\mathrm{EP}_{\mathrm{S}_{-} \mathrm{CP}}(\mathrm{Q}, e)=(1-\phi) e[(r-c) q-(r-v) n(q)]-(1-\lambda) \beta e^{2}$ \\
\hline & MD & $\mathrm{EP}_{\mathrm{S}_{-} \mathrm{NB}}(Q, e)=e[(w-c) Q-m n(Q)]-(1-\lambda) \beta e^{2}$ \\
\hline \multirow{2}{*}{ Supply chain } & PS & $\mathrm{EP}_{\mathrm{SC} \_\mathrm{CP}}(Q, e)=e[(r-c) Q-(r-v) n(Q)]-\beta e^{2}$ \\
\hline & $\mathrm{MD}$ & $\mathrm{EP}_{\mathrm{SC}_{-} \mathrm{NB}}(Q, e)=e[(r-c) Q-(r-v) n(Q)]-\beta e^{2}$ \\
\hline
\end{tabular}

Notes. $n(Q)=\int_{0}^{Q} F(x) d x$.

(ii) $\Delta_{R \_P S}\left(q_{S C \_P S}^{*}\right)=\Delta_{R \_M D}\left(q_{S C \_M D}^{*}\right)$ and $\Delta_{S \_P S}\left(q_{S C \_P S}^{*}\right)=$ $\Delta_{S \_M D}\left(q_{S C_{-} M D}^{*}\right)$.

Recall that SP represents the "absolute risk" and CV represents the "relative risk." It is interesting to note from Proposition 5(ii) that the supply chain parties are receiving the same relative risk under the coordinating $\mathrm{MD}$ and the coordinating PS contracts. In other words, if a supply chain agent only considers the relative risk as the measure for their business performance, developing a private label is equivalent to selling to the national brand.

On the other hand, when the retailer cares about the absolute risk, Proposition 5(i) indicates that the choice of the contract depends on the relationship between the markdown price $m$ and the gross profit sharing ratio $\phi$. Specifically, for a risk-averse retailer, when $m \geq(1-\phi)(r-v)$, the $\mathrm{MD}$ contract is more preferable since it results in a smaller SP; similarly, it will prefer to adopt the PS contract when $m<(1-\phi)(r-v)$. Moreover, the product's unit retail price $(r)$ would also affect the risk-averse retailer's decision on contract selection. Specifically, if $r$ is sufficiently high, the risk-averse retailer would prefer the PS contract. In this paper, we consider the unit retail price is exogenous and is the same for both type of suppliers (namely, the national brand and the private label). In reality, products of private labels are more expensive than those of the national brands in general. Therefore, the condition of $m<(1-\phi)(r-v)$ is more likely to hold for the private label. As a result, the risk- averse retailer should adopt the PS contract with the private label. On the contrary, the condition of $m \geq(1-\phi)(r-v)$ is more likely to hold for the national brand. In turn, the risk-averse retailer should adopt the MD contract with the national brand. These findings are consistent with the real practices observed in the fashion industry.

\section{Impacts of Sales Effort on Supply Chain Coordination (SCC)}

In this section, we study how the retailer's sales effort, as a costly action, affects the performance of supply chain under the PS and MD contracts, respectively. It is well-known that the retailer's sales effort (such as in-store mechanizing, advertising, direct mail, point-of-sale information, targeted discounts, and free gift wrapping) can influence the market demand [18-21]. Here, following the literature, we consider that the retailer's sales effort has a positive impact on the market demand. Specifically, we formulate the sales-effortenhanced market demand in the form of $D(e)=e x$, where $e \geq 1$ is the level of sales effort in selling the product and same as Section 3, the inherent demand $x$ is a random variable with a probability density function (p.d.f.) $f(x)$, and a corresponding cumulative density function (c.d.f.) $F(x)$ defined over the continuous interval $[0, \infty)$. This type of multiplicative effort-demand model is also used in Taylor [18], Krishan et al. [21], Gurnani and Erkoc [19], and Chiu et al. [20]. The cost to the retailer of exerting $e$ units of effort is $C(e)$, which is convex and strictly increasing in $e$; that is, $d C(e) / d e>0$ and $d^{2} C(e) / d e^{2}>0$. In order to obtain closeform analytical insights, we consider $C(e)=\beta e^{2}$, where $\beta>$ 0 . The function of the cost of effort is also adopted in Gurnani and Erkoc [19].

Similar to the settings in the previous section, the supplier is the Stackelberg leader who decides the contract parameters and sales effort $(e)$ whilst the retailer is the follower who decides the order quantity $(q)$. Let $\lambda$ be the proportion of the sales effort cost to be incurred to the retailer, where $\lambda \in[0,1]$. If the supplier is willing to share the cost of the retailer's sales effort, $0 \leq \lambda<1$. Correspondingly, the retailer incurs $\lambda \beta e^{2}$ as the sales effort cost whereas the supplier is responsible for the remaining portion, $(1-\lambda) \beta e^{2}$. On the other hand, if the supplier is not willing to share the sales effort cost, $\lambda=1$. We consider that both the order quantity and the level of sales effort are decided prior to observing the state of the market demand. Define $Q=q / e$. The expressions of the EP and SP for all parties under the PS and the MD contracts with $Q$ and $e$ are shown in Table 2. (As a remark, we do not consider SP in this section due to similarity in the findings in the last section).

We denote by $\left(Q_{\mathrm{SC} \_}^{*}, e_{\mathrm{SC} \_}^{*}\right)$ and $\left(Q_{\mathrm{R} l}^{*}, e_{\mathrm{R} \_}^{*}\right)$ the optimal joint decision that maximizes the supply chain's and retailer's EP under $l$ contract in the decentralized setting, respectively. Let $q_{\mathrm{SC} l}^{*}=Q_{\mathrm{SC} l}^{*} e_{\mathrm{SC} l}^{*}$ and $q_{\mathrm{R} l}^{*}=Q_{\mathrm{R} l}^{*} e_{\mathrm{SC} l}^{*}$.

Solving the simultaneous first-order conditions with respect to $Q$ and $e$, the optimal sales effort to the centralized supply chain, is given by

$$
e_{\mathrm{SC} \perp}^{*}=\frac{\left[(r-c) Q_{\mathrm{SC} \perp}^{*}-(r-v) n\left(Q_{\mathrm{SC} \perp}^{*}\right)\right]}{(2 \beta)}
$$

where $Q_{\mathrm{SC} \perp}^{*}=F^{-1}[(r-c) /(r-v)]$. 
For the decentralized supply chain, the retailer's optimal sales effort under the PS contract is

$$
e_{\mathrm{R} \_\mathrm{PS}}^{*}=\frac{\phi\left[(r-c) Q_{\mathrm{R} \_\mathrm{PS}}^{*}-(r-v) n\left(\mathrm{Q}_{\mathrm{R} \_\mathrm{PS}}^{*}\right)\right]}{(2 \lambda \beta)},
$$

where $Q_{R_{-} P S}^{*}=F^{-1}[(r-c) /(r-v)]$, and that of the MD is

$$
e_{\mathrm{R} \_M D}^{*}=\frac{\left[(r-w) Q_{\mathrm{R} \_M D}^{*}-(r-m-v) n\left(Q_{\mathrm{R} \_M D}^{*}\right)\right]}{(2 \lambda \beta)},
$$

where $Q_{\mathrm{R} \_\mathrm{MD}}^{*}=F^{-1}[(r-w) /(r-m-v)]$.

Similar to the scenario without sales effort consideration, the MD contract is equivalent to the PS contract from the supply chain perspective with the retailer's effort-induced demand. However, our simple observation implies that the supply chain cannot be coordinated with sales effort consideration. Naturally, how we can coordinate supply chain with sales effort consideration becomes an interesting question.

Now we consider the impact of the supplier's willingness to share the cost of sales effort on the supply chain performance. We use the superscripts NS and ES to denote the case when the supplier is not willing to bear the sales effort cost (i.e., $\lambda=1$ ) and the case when it is willing to bear the sales effort cost (i.e., $\lambda \neq 1$ ), respectively. We compare the two cases under the coordinating PS and MD contracts in the decentralized setting, respectively.

We have the following definition: the ES case is said to dominate the NS case (i.e., ES is a dominating strategy) if and only if $E \pi_{k-l}^{\mathrm{ES}}>E \pi_{k-l}^{\mathrm{NS}}$ for $k \in\{\mathrm{R}, \mathrm{S}\}$ and $l \in\{\mathrm{PS}, \mathrm{MD}\}$. We have the following proposition.

Proposition 6. (i) For the retailer, $E \pi_{R E S}\left(Q_{R_{l} l}^{*}, e_{R_{-} l}^{*}\right)>$ $E \pi_{R_{-} N S}\left(Q_{R_{l} l}^{*}, e_{R_{-} l}^{*}\right)$ for all $l \in\{P S, M D\}$. (ii) For the supplier, $E \pi_{S_{-} E S}\left(Q_{R_{-} P S}^{*}, e_{R_{-} P S}^{*}\right)>E \pi_{S_{\perp} N S}\left(Q_{R_{-} P S}^{*}, e_{R_{-} P S}^{*}\right)$ if and only if the contract parameters satisfy $\phi<2 \lambda /(1+2 \lambda)$; $E \pi_{S_{\perp} S}\left(Q_{R_{-} M D}^{*}, e_{R_{-} M D}^{*}\right)>E \pi_{S_{-N S}}\left(Q_{R_{-} M D}^{*}, e_{R_{-} M D}^{*}\right)$ if and only if the contract parameters satisfy $(r-w)(r-v)=(r-m-v)(r-$ c) and $m>(r-v) /(1+2 \lambda)$.

From Proposition 6(i), we can see that the retailer under the case of ES always dominates that of NS. This implies that the retailer always prefers the supplier to share the cost of sales effort so that it can be better off. For the supplier, if the conditions in Proposition 6(ii) are satisfied, the case of ES will be dominating. In other words, with the specified conditions satisfied, the supplier should be willing to share the cost of sales effort to be better off. Concluding the results of both Proposition 6(i) and (ii), both parties could be better off with the supplier giving a partial support on the sales effort cost.

Proposition 6(i) and (ii) provide an important implication for the fashion industry. In real practices, it is common for a fashion department store (e.g., J. C. Penney) to be fully responsible for all kinds of sales effort so as to attract a strong supplier (national brand or private label) for business cooperation. Our results indicate that such practice might not be optimal to both parties. Counterintuitively, our analytical findings suggest that both parties can be better off if the supplier is willing to bear the cost of the sales effort partially.
We define that the mechanism of supply chain coordination with sales effort consideration is to satisfy both $e_{\mathrm{R} \_l}^{*}=e_{\mathrm{SC} \_}^{*}$ and $\mathrm{Q}_{\mathrm{R} \_}^{*}=Q_{\mathrm{SC} \_l}^{*}$ simultaneously. Thus we have Proposition 7.

Proposition 7. (i) The supply chain with retailer's sales effort can be coordinated under the PS contract and the MD contract when $\lambda \neq 1$; (ii) under channel coordination, the optimal portion of profit sharing under the PS contract is $\phi^{*}=\lambda$; and the optimal markdown price under the MD contract: $m^{*}=$ $\left[\left(w^{*}-c\right)(r-v) /(r-c)\right]$ and $m^{*}=(r-v)(1-\lambda)$.

Proposition 7(i) asserts that an important factor for the supply chain to be coordinated is that the supplier is willing to share the cost of sales effort. This finding implies that the value of cooperation such as sharing the cost of sales effort within supply chain is significant for the supply chain parties to achieve the best payoff. In Proposition 7(ii), we find that when $\phi^{*}=\lambda$, it helps the supply chain achieve channel coordination, that is, if the supplier takes the responsibility of sharing the cost of sales effort for the same portion as profit sharing. Under the coordinating MD contract, we find that the optimal markdown price $m^{*}$ is decreasing with $\lambda$. In other words, a higher portion of cost sharing by the supplier implies a higher optimal markdown price he should offer.

\section{Managerial Insights and Conclusion}

This paper has studied the supply chain contracting games in fashion department stores in which they sell national brands under the MD contract or develop private labels under the PS contract. A well-known supplier-retailer channel facing unknown demand has been investigated. How sales effort consideration affects supply chain coordination under the corresponding contracts has been explored. To summarize, our analysis has derived the following key findings. First, we have found the necessary and sufficient conditions for achieving supply chain coordination under the MD and PS contracts, respectively. Second, we have analytically compared the differences and similarities between the MD and the PS contracts and revealed that there is an equivalent relative level of risk but a different absolute level of risk for supply chain agents between the MD and the PS cases (when the supply chain is coordinated). This result further implies that if the retailer is the contract selector, for a high retail price product (e.g., luxury fashion items), the risk-averse retailer is more likely to sell the private label, whereas for a low retail price product (e.g., mass fashion items), the risk-averse retailer is more likely to sell the national brand. As a matter of fact, it is well-known that, nowadays, the supply chain agents, particularly the retailers, are more risk-averse than before because of financial tsunami in 2008 [10]. This finding fits the real situation well and provides an important implication for operations management of fashion department stores. Fourth, after considering the sales effort in market demand, the supply chain can be coordinated if and only if the supplier is willing to share the cost of sales effort. As such, in order to obtain a better payoff, cooperation such as sharing the cost of sales effort is crucial to achieve coordination. 
Note that this study is subject to two main limitations that point toward fruitful directions for future research. First, we consider that the retail price is exogenous because we focus on studying the impact of contract parameters on supply chain coordination. Second, we consider the case in which national brand and private label are independent in the market because we focus on studying the contract property of the $\mathrm{PS}$ and the MD contracts in this research. In future research, it is worth investigating other kinds of fashion supply chain contracts and strategies [23-30]. Moreover, sustainability has been a popular topic in fashion. It would be interesting to study the sustainability issues in department fashion stores [31-33]. Last but not least, it would be important to explore a longer supply chain with the upstream manufacturing and supplying side taken in full consideration (e.g., see Yeung et al. [34]).

\section{Appendix}

\section{All Proofs}

Proof of Lemma 1. We firstly discuss the retailer's optimal quantity decision on the PS by taking the first and the second derivatives of $\mathrm{EP}_{\mathrm{R}_{-} \mathrm{CP}}(q)$ with respect to $q$ and yield the expressions below:

$$
\begin{aligned}
& \frac{\partial \mathrm{EP}_{\mathrm{R}_{-} \mathrm{CP}}(q)}{\partial q}=\phi[(r-c)-(r-v) F(q)], \\
& \frac{\partial^{2} \mathrm{EP}_{\mathrm{R} \_\mathrm{PS}}(q)}{\partial q^{2}}=\phi[-(r-v) f(q)]<0 .
\end{aligned}
$$

Then we discuss the supply chain's optimal quantity on the PS by taking the first and the second derivatives of EP with respect to $q$ and yield the expressions below:

$$
\begin{aligned}
& \frac{\partial \mathrm{EP}_{\mathrm{SC}_{-} \mathrm{CP}}(q)}{\partial q}=[(r-c)-(r-v) F(q)], \\
& \frac{\partial^{2} \mathrm{EP}_{\mathrm{SC}_{-} \mathrm{CP}}(q)}{\partial q^{2}}=\frac{\partial^{2} \mathrm{EP}_{\mathrm{R}_{-} \mathrm{CP}}(q)}{\partial q^{2}}=[-(r-v) f(q)]<0 .
\end{aligned}
$$

We find that $\operatorname{EP}_{\mathrm{R}_{-} \mathrm{CP}}(q)$ and $\mathrm{EP}_{\mathrm{SC}_{-} \mathrm{CP}}(q)$ are strictly concave in $q$; the optimal quantities are obtained when the first derivatives of EP with respect to $q$ is equal to zero. According to the mechanism of channel coordination $q_{\mathrm{R}}^{*}=q_{\mathrm{SC}}^{*}$, we obtain Lemma 1.

Proof of Proposition 2. We substitute $q_{\mathrm{R}_{-} \mathrm{CP}}^{*}$ into both EPs and SPs of supplier, retailer, and supply chain. We have the following expressions:

$$
\begin{aligned}
& \operatorname{EP}_{\mathrm{R}_{-} \mathrm{CP}}\left(q_{\mathrm{R}_{-} \mathrm{CP}}^{*}\right) \\
& \quad=\phi\left[(r-c) F^{-1}\left[\frac{(r-c)}{(r-v)}\right]-(r-v) n\left(F^{-1}\left[\frac{(r-c)}{(r-v)}\right]\right)\right],
\end{aligned}
$$

$$
\begin{gathered}
\operatorname{EP}_{\mathrm{S}_{-} \mathrm{CP}}\left(q_{\mathrm{R} \_\mathrm{CP}}^{*}\right)=(1-\phi)\left[(r-c) F^{-1}\left[\frac{(r-c)}{(r-v)}\right]\right. \\
\left.-(r-v) n\left(F^{-1}\left[\frac{(r-c)}{(r-v)}\right]\right)\right], \\
\mathrm{SP}_{\mathrm{R}_{-} \mathrm{CP}}\left(q_{\mathrm{R} \_\mathrm{CP}}^{*}\right)=\phi(r-v) \sqrt{\xi\left(F^{-1}\left[\frac{(r-c)}{(r-v)}\right]\right)}, \\
\mathrm{SP}_{\mathrm{S}_{-} \mathrm{CP}}\left(q_{\mathrm{SC} \_\mathrm{CP}}^{*}\right)=(1-\phi)(r-v) \sqrt{\xi\left(F^{-1}\left[\frac{(r-c)}{(r-v)}\right]\right)} .
\end{gathered}
$$

Thus, we simply obtain Proposition 2(i). We then calculate the supply chain parties' $\mathrm{CV}\left(\mathrm{SP}_{i}(q) / \mathrm{EP}_{i}(q)\right)$ and obtain Proposition 2(ii)

Proof of Proposition 3. We substitute $q_{\mathrm{SC} \text { NB }}^{*}$ into $\operatorname{EP}_{\mathrm{S}}(q)$ and $\operatorname{EP}_{\mathrm{R}}(q)$ which yields

$$
\begin{aligned}
& \mathrm{EP}_{\mathrm{R}}\left(q_{\mathrm{SC} \_\mathrm{NB}}^{*}\right) \\
& =\left(1-\frac{m^{*}}{r-v}\right)\left[(r-c) q_{\mathrm{SC} \_\mathrm{NB}}^{*}-(r-v) n\left(q_{\mathrm{SC} \_\mathrm{NB}}^{*}\right)\right] \\
& \mathrm{EP}_{\mathrm{S}}\left(q_{\mathrm{SC} \_\mathrm{NB}}^{*}\right) \\
& =\left(\frac{m^{*}}{r-v}\right)\left[(r-c) q_{\mathrm{SC} \_\mathrm{NB}}^{*}-(r-v) n\left(q_{\mathrm{SC} \_\mathrm{NB}}^{*}\right)\right] .
\end{aligned}
$$

Thus, Proposition 3(i) is observed.

Since supply chain coordination needs the condition of $(r-w)(r-v)=(r-c)(r-m-v)$, we substitute $K^{*}$ into the condition and yield $K^{*}=w^{*}-r+v+\left(\left(r-w^{*}\right)(r-v) /(r-c)\right)$ or $K^{*}=r-m^{*}-\left(\left(r-m^{*}-v\right)(r-c) /(r-v)\right)$. After reorganizing them, we have the following equations:

$$
\begin{gathered}
K^{*}=v+\frac{\left(r-w^{*}\right)(c-v)}{(r-c)}, \\
K^{*}=\frac{\left(r-m^{*}\right)(c-v)+(r-c) v}{r-v} .
\end{gathered}
$$

Proposition 3(i) is observed.

Proof of Proposition 4. We compare the retailer's and the supply chain's optimal quantity on the MD and PS, respectively. We observe that if $m \leq[(w-c)(r-v)] /(r-c)$, we have $q_{\mathrm{R} \_\mathrm{PS}}^{*} \geq$ $q_{\mathrm{R} \_\mathrm{MD}}^{*}$; otherwise, $q_{\mathrm{R} \_\mathrm{PS}}^{*}<q_{\mathrm{R} \_\mathrm{MD}}^{*}$. Hence Proposition 4(i) and (ii) are obtained. Based on the supply chain's optimal quantity on the MD and the PS, respectively, we easily obtain Proposition 4(iii). According to Proposition 4(iii), we find Proposition 4(iv) that both EP and SP of supply chain on the $\mathrm{PS}$ are equal to the ones on the MD. We then calculate the CV on the MD and the PS, respectively, and we simply find that the supply chain's CV under the PS is equal to that under the $\mathrm{MD}$ 
Proof of Proposition 5. We substitute $q_{\mathrm{SC} \perp \mathrm{MD}}^{*}$ and $q_{\mathrm{SC} \_\mathrm{PS}}^{*}$ into the supply chain parties' EP and their SP under the MD and the PS. We have the following expressions under the coordinating supply chain:

$$
\begin{aligned}
& \mathrm{EP}_{\mathrm{R}}\left(q_{\mathrm{SC} \_\mathrm{CP}}^{*}\right)=\phi \mathrm{EP}_{\mathrm{SC}}\left(q_{\mathrm{SC} \_\mathrm{CP}}^{*}\right), \\
& \mathrm{SP}_{\mathrm{R}}\left(q_{\mathrm{SC} \_\mathrm{CP}}^{*}\right)=\phi \mathrm{SP}_{\mathrm{SC}}\left(q_{\mathrm{SC} \_\mathrm{CP}}^{*}\right) \text {; } \\
& \mathrm{EP}_{\mathrm{S}}\left(q_{\mathrm{SC} \_ \text {CP }}^{*}\right)=(1-\phi) \mathrm{EP}_{\text {SC }}\left(q_{\text {SC_CP }}^{*}\right) \text {, } \\
& \mathrm{SP}_{\mathrm{S}}\left(q_{\mathrm{SC} \_\mathrm{CP}}^{*}\right)=(1-\phi) \mathrm{SP}_{\mathrm{SC}}\left(q_{\mathrm{SC} \_\mathrm{CP}}^{*}\right) \text {; } \\
& \mathrm{EP}_{\mathrm{R}}\left(q_{\mathrm{SC} \_\mathrm{NB}}^{*}\right)=\left(1-\frac{m}{r-v}\right) \mathrm{EP}_{\mathrm{SC}}\left(q_{\mathrm{SC} \_\mathrm{NB}}^{*}\right), \\
& \operatorname{SP}_{\mathrm{R}}\left(q_{\mathrm{SC} \_\mathrm{MD}}^{*}\right)=\left(1-\frac{m}{r-v}\right) \mathrm{SP}_{\mathrm{SC}}\left(q_{\mathrm{SC} \_ \text {MD }}^{*}\right) ; \\
& \mathrm{EP}_{\mathrm{S}}\left(q_{\mathrm{SC} \_\mathrm{NB}}^{*}\right)=\left(\frac{m}{r-v}\right) \mathrm{EP}_{\mathrm{SC}}\left(q_{\mathrm{SC} \_\mathrm{NB}}^{*}\right), \\
& \mathrm{SP}_{\mathrm{S}}\left(q_{\mathrm{S} C \_N B}^{*}\right)=\frac{m}{r-v} \mathrm{SP}_{\mathrm{SC}}\left(q_{\mathrm{SC} \_\mathrm{NB}}^{*}\right) .
\end{aligned}
$$

After comparing their EP and SP, we simply obtain Proposition 5(i) and (ii). We then calculate the corresponding $\mathrm{CV}$ and obtain Proposition 5(iii).

Proof of Proposition 6. We discuss the optimal sales effort by taking the first and the second derivatives of retailer's and supply chain's EP with respect to $Q$ and $e$. We have the expressions for the retailer and the whole supply chain below.

Supply chain is

$$
\begin{aligned}
& \frac{d \mathrm{EP}_{\mathrm{SC} \_l}(\mathrm{Q}, e)}{d \mathrm{Q}}=e[(r-c)-(r-v) F(Q)], \\
& \frac{d^{2} \mathrm{EP}_{\mathrm{SC} l}(Q, e)}{d Q^{2}}=-e(r-v) F(Q)<0, \\
Q_{\mathrm{SC} \_l}^{*} & =\arg \{e[(r-c)-(r-v) F(Q)]\} \\
& =F^{-1}\left[\frac{(r-c)}{(r-v)}\right] .
\end{aligned}
$$

Substituting $Q_{\mathrm{SC} \perp}^{*}$ into $\operatorname{EP}_{\mathrm{SC}_{\perp}}(\mathrm{Q}, e)$ and taking the derivative with respect to $e$ yield $e_{\mathrm{SC}\rfloor}^{*}=\left[(r-c) Q_{\mathrm{SC}\rfloor}^{*}-(r-\right.$ v) $\left.\int_{0}^{\mathrm{Q}_{\mathrm{SC} \perp}^{*}} F(x) d x\right] / 2 \beta$, where $Q_{\mathrm{SC} \perp}^{*}=F^{-1}[(r-c) /(r-v)]$.

Retailer under the PS and the MD.

Similar to the approach above, we can have

$$
\begin{aligned}
Q_{\mathrm{R}_{-} \mathrm{CP}}^{*} & =F^{-1}\left[\frac{(r-c)}{(r-v)}\right], \\
e_{\mathrm{R}_{\mathrm{C} P}}^{*} & =\frac{\phi\left[(r-c) Q_{\mathrm{R}_{-} \mathrm{CP}}^{*}-(r-v) n\left(Q_{\mathrm{R}_{-} \mathrm{CP}}^{*}\right)\right]}{2 \lambda \beta}, \\
\mathrm{Q}_{\mathrm{R}_{-} \mathrm{NB}}^{*} & =F^{-1}\left[\frac{(r-w)}{(r-m-v)}\right], \\
e_{\mathrm{R} \_\mathrm{NB}}^{*} & =\frac{\left[(r-w) Q_{\mathrm{R}_{-} \mathrm{NB}}^{*}-(r-m-v) n\left(Q_{\mathrm{R} \_\mathrm{NB}}^{*}\right)\right]}{2 \lambda \beta} .
\end{aligned}
$$

We substitute $\left(Q_{\mathrm{R} \_}^{*}, e_{\mathrm{R} \_}^{*}\right)$ into the supply chain parties' EPs and yield the expressions below:

$$
\begin{aligned}
& \operatorname{NS}(\lambda=1) \text { : } \\
& \mathrm{EP}_{\mathrm{R} \_ \text {NS }}\left(Q_{\mathrm{R}_{-} \mathrm{CP}}^{*}, e_{\mathrm{R} \_\mathrm{CP}}^{*}\right) \\
& =\frac{\phi^{2}\left[(r-c) Q_{\mathrm{R}_{-} \mathrm{CP}}^{*}-(r-v) n\left(Q_{\mathrm{R}-\mathrm{CP}}^{*}\right)\right]^{2}}{(4 \beta)}, \\
& \mathrm{EP}_{\mathrm{S}_{-} \mathrm{NS}}\left(Q_{\mathrm{R}_{-} \mathrm{CP}}^{*}, e_{\mathrm{R} \_\mathrm{CP}}^{*}\right) \\
& =(1-\phi) \frac{\phi\left[(r-c) Q_{\mathrm{R}_{-} \mathrm{CP}}^{*}-(r-v) n\left(Q_{\mathrm{R}_{-} \mathrm{CP}}^{*}\right)\right]^{2}}{(2 \beta)}, \\
& \mathrm{EP}_{\mathrm{R} \_\mathrm{NS}}\left(Q_{\mathrm{R} \_\mathrm{NB}}^{*}, e_{\mathrm{R} \_\mathrm{NB}}^{*}\right) \\
& =\frac{\left[(r-w) Q_{\mathrm{R} \_\mathrm{NB}}^{*}-(r-m-v) n\left(\mathrm{Q}_{\mathrm{R} \_\mathrm{NB}}^{*}\right)\right]^{2}}{(4 \beta)}, \\
& \mathrm{EP}_{\mathrm{S} \_\mathrm{NS}_{\mathrm{N}}}\left(Q_{\mathrm{R} \_\mathrm{NB}}^{*}, e_{\mathrm{R} \_\mathrm{NB}}^{*}\right) \\
& =\left(\left[(w-c) Q_{\mathrm{R}_{-} \mathrm{NB}}^{*}-m n\left(Q_{\mathrm{R}_{\_} \mathrm{NB}}^{*}\right)\right]\right. \\
& \left.\times\left[(r-w) Q_{\mathrm{R}_{-} \mathrm{NB}}^{*}-(r-m-v) n\left(Q_{\mathrm{R}_{-} \mathrm{NB}}^{*}\right)\right]\right) \\
& \times(2 \beta)^{-1},
\end{aligned}
$$

$\mathrm{ES}(\lambda \neq 1)$ :

$$
\begin{aligned}
& \operatorname{EP}_{\mathrm{R}_{E} E S}\left(Q_{\mathrm{R}_{-} \mathrm{CP}}^{*}, e_{\mathrm{R}_{-} \mathrm{CP}}^{*}\right) \\
& =\frac{\phi^{2}\left[(r-c) Q_{\mathrm{R}_{-} \mathrm{CP}}^{*}-(r-v) n\left(Q_{\mathrm{R} \_\mathrm{CP}}^{*}\right)\right]^{2}}{4 \lambda \beta},
\end{aligned}
$$

$\mathrm{EP}_{\mathrm{S} \_\mathrm{ES}_{\mathrm{B}}}\left(Q_{\mathrm{R} \_\mathrm{CP}}^{*}, e_{\mathrm{R} \_\mathrm{CP}}^{*}\right)$

$$
\begin{aligned}
= & {\left[(1-\phi)-\frac{(1-\lambda) \phi}{2 \lambda}\right] } \\
& \times \frac{\left[(r-c) Q_{\mathrm{R}_{-} \mathrm{CP}}^{*}-(r-v) n\left(Q_{\mathrm{R}_{-} \mathrm{CP}}^{*}\right)\right]^{2} \phi}{2 \lambda \beta},
\end{aligned}
$$

$\mathrm{EP}_{\mathrm{R} \_\mathrm{ES}}\left(Q_{\mathrm{R} \_\mathrm{NB}}^{*}, e_{\mathrm{R} \_\mathrm{NB}}^{*}\right)$

$$
=\frac{\left[(r-w) Q_{\mathrm{R} \_\mathrm{NB}}^{*}-(r-m-v) n\left(Q_{\mathrm{R} \_\mathrm{NB}}^{*}\right)\right]^{2}}{4 \lambda \beta},
$$

$$
\begin{aligned}
\mathrm{EP}_{\mathrm{S}_{\perp} \mathrm{ES}} & \left(Q_{\mathrm{R}_{\_} \mathrm{NB}}^{*}, e_{\mathrm{R} \_\mathrm{NB}}^{*}\right) \\
= & \left(\left[(w-c) Q_{\mathrm{R}_{-} \mathrm{NB}}^{*}-m n\left(\mathrm{Q}_{\mathrm{R} \_\mathrm{NB}}^{*}\right)\right]\right. \\
& \left.\times\left[(r-w) Q_{\mathrm{R}_{-} \mathrm{NB}}^{*}-(r-m-v) n\left(Q_{\mathrm{R} \_\mathrm{NB}}^{*}\right)\right]\right) \\
& \times(2 \lambda \beta)^{-1} \\
& \quad \frac{(1-\lambda)\left[(r-w) Q_{\mathrm{R} \_\mathrm{NB}}^{*}-(r-m-v) n\left(Q_{\mathrm{R} \_\mathrm{NB}}^{*}\right)\right]^{2}}{4 \lambda^{2} \beta}, \\
2 \lambda & {\left[(w-c) Q_{\mathrm{R} \_\mathrm{NB}}^{*}-m n\left(Q_{\mathrm{R} \_\mathrm{NB}}^{*}\right)\right] } \\
> & {\left[(r-w) Q_{\mathrm{R} \_\mathrm{NB}}^{*}-(r-m-v) n\left(Q_{\mathrm{R} \_\mathrm{NB}}^{*}\right)\right] . }
\end{aligned}
$$


We compare ES cases with NS ones. Since $\lambda \in(0,1]$, we have

$$
\begin{aligned}
& E \pi_{\mathrm{R}_{\mathrm{ESS}}}\left(Q_{\mathrm{R}_{-} \mathrm{CP}}^{*}, e_{\mathrm{R} \_\mathrm{CP}}^{*}\right)>E \pi_{\mathrm{R}_{-} \mathrm{NS}}\left(Q_{\mathrm{R}_{-} \mathrm{CP}}^{*}, e_{\mathrm{R} \_\mathrm{CP}}^{*}\right) \text {, } \\
& E \pi_{\mathrm{R} \_\mathrm{ES}}\left(Q_{\mathrm{R} \_\mathrm{NB}}^{*}, e_{\mathrm{R} \_\mathrm{NB}}^{*}\right)>E \pi_{\mathrm{R} \_\mathrm{NS}}\left(Q_{\mathrm{R} \_\mathrm{NB}}^{*}, e_{\mathrm{R} \_\mathrm{NB}}^{*}\right) .
\end{aligned}
$$

Comparing the supplier's optimal profit in ES with the one in NS for the PS, we have if $E \pi_{\mathrm{S}_{-} \mathrm{ES}}\left(Q_{\mathrm{R}_{-} \mathrm{CP}}^{*}, e_{\mathrm{R}_{-} \mathrm{CP}}^{*}\right)>$ $E \pi_{\mathrm{S}_{\mathrm{N} S}}\left(Q_{\mathrm{R}_{-} \mathrm{CP}}^{*}, e_{\mathrm{R}_{\mathrm{CP}}}^{*}\right)$, namely, $\phi<2 \lambda /(1+2 \lambda)$, thus we obtain Proposition 6(i)

For the MD, we also compare the supplier's optimal profit in ES with the one in NS; we have if $E \pi_{S_{-} E S}\left(Q_{R_{2} N B}^{*}, e_{R_{-} N B}^{*}\right)>$ $E \pi_{\mathrm{S}_{\mathrm{N} S}}\left(Q_{\mathrm{R}_{-} \mathrm{NB}}^{*}, e_{\mathrm{R} \_\mathrm{NB}}^{*}\right)$, the contract parameters can satisfy

$$
\begin{gathered}
(r-w)(r-v)=(r-m-v)(r-c), \\
m>\frac{(r-v)}{(1+2 \lambda)} .
\end{gathered}
$$

Proof of Proposition 7. Since the mechanism of supply chain coordination with sales effort consideration is $e_{\mathrm{R} l}^{*}=$ $e_{\mathrm{S} \_l}^{*}$ and $\mathrm{Q}_{\mathrm{R} \_}^{*}=\mathrm{Q}_{\mathrm{SC} \_l}^{*}$, recall Equations (A.7), (A.8), and (A.9), we can obtain under channel coordination, the optimal portion of profit sharing under the PS contract is: $\phi^{*}=\lambda$; and the optimal markdown price under the MD contract is:

$$
m^{*}=\left[\frac{\left(w^{*}-c\right)}{(r-v)}\right] \text { and } m^{*}=(r-v)(1-\lambda)
$$

\section{Conflict of Interests}

The authors declare that there is no conflict of interests with the named companies regarding the publication of this paper.

\section{Authors' Contribution}

All of the authors made substantial contributions to this paper; the authors are listed in reverse alphabetical order by surnames, with the senior author listed last.

\section{Acknowledgments}

Bin Shen's research is sponsored by the Shanghai Pujiang Program (14PJ1400200) and the Fundamental Research Funds for the Central Universities. Tsan-Ming Choi's research is partially supported by the research grants of G-YK71 and GUA1Q.

\section{References}

[1] T. Rozhon, "First the markdown, then the showdown," The New York Times, 2005.

[2] E. Clark, "New Life for Liz: Claiborne Goes Exclusive to Penney's, QVC," Women's Wear Daily, October 20009, http:// www.wwd.com/business-news/financial/new-life-for-liz-claiborne-goes-exclusive-to-penneys-qvc-2338294.
[3] Y. Wei and T. M. Choi, "Mean-variance analysis of supply chains under wholesale pricing and profit sharing schemes," European Journal of Operational Research, vol. 204, no. 2, pp. 255-262, 2010.

[4] N. Kumar and J. B. Steenkamp, Private Label Strategy: How to Meet the Store Brand Challenge, Harvard Business School Press, Cambridge, Mass, USA, 2007.

[5] G. Cachon, "Supply chain coordination with contracts," in Handbooks in Operations Research and Management Science: Supply Chain Management, S. Graves and T. de Kok, Eds., North-Holland, New York, NY, USA, 2003.

[6] T. M. Choi, D. Li, and H. Yan, "Mean-variance analysis of a single supplier and retailer supply chain under a returns policy," European Journal of Operational Research, vol. 184, no. 1, pp. 356-376, 2008.

[7] W. Hausman and J. Thorbeck, "Fast fashion: quantifying the benefits," in Innovative Quick Response Programs in Logistics and Supply Chain Management, vol. 4 of International Handbooks Information System, pp. 315-329, Springer, Berlin, Germany, 2010.

[8] Z. Ning, T. M. Choi, C. Xie, L. Xie, and J. Dai, "Impact of emarketplace on supply chain under markdown policy," Supply Chain Management, vol. 16, no. 6, pp. 409-418, 2011.

[9] C. X. Wang and S. Webster, "Markdown money contracts for perishable goods with clearance pricing," European Journal of Operational Research, vol. 196, no. 3, pp. 1113-1122, 2009.

[10] B. Shen, T. M. Choi, Y. Wang, and C. Lo, "The coordination of fashion supply chains with a risk-averse supplier under the markdown money policy," IEEE Transactions on Systems, Man, and Cybernetics: Systems, vol. 43, no. 2, pp. 266-276, 2013.

[11] A. P. Jeuland and S. M. Shugan, "Managing channel profits," Marketing Science, vol. 27, no. 1, pp. 49-51, 2008.

[12] M. Y. Jaber and I. H. Osman, "Coordinating a two-level supply chain with delay in payments and profit sharing," Computers and Industrial Engineering, vol. 50, no. 4, pp. 385-400, 2006.

[13] M. Leng and M. Parlar, "Lead-time reduction in a two-level supply chain: non-cooperative equilibria vs. coordination with a profit-sharing contract," International Journal of Production Economics, vol. 118, no. 2, pp. 521-544, 2009.

[14] A. A. Tsay, "Managing retail channel overstock: markdown money and return policies," Journal of Retailing, vol. 77, no. 4, pp. 457-492, 2001.

[15] B. A. Pasternack, "Optimal pricing and return policies for perishable commodities," Marketing Science, vol. 27, no. 1, pp. 133-140, 2008.

[16] H. Lau and A. H. Lau, "Manufacturer's pricing strategy and return policy for a single-period commodity," European Journal of Operational Research, vol. 116, no. 2, pp. 291-304, 1999.

[17] G. P. Cachon and M. A. Lariviere, "Supply chain coordination with revenue-sharing contracts: strengths and limitations," Management Science, vol. 51, no. 1, pp. 30-44, 2005.

[18] T. A. Taylor, "Supply chain coordination under channel rebates with sales effort effects," Management Science, vol. 48, no. 8, pp. 992-1007, 2002.

[19] H. Gurnani and M. Erkoc, "Supply contracts in manufacturerretailer interactions with manufacturer-quality and retailer effort-induced demand," Naval Research Logistics, vol. 55, no. 3, pp. 200-217, 2008.

[20] C. Chiu, T. M. Choi, and X. Li, "Supply chain coordination with risk sensitive retailer under target sales rebate," Automatica, vol. 47, no. 8, pp. 1617-1625, 2011. 
[21] H. Krishnan, R. Kapuscinski, and D. A. Butz, "Coordinating Contracts for Decentralized Supply Chains with Retailer Promotional Effort," Management Science, vol. 50, no. 1, pp. 48-63, 2004.

[22] G. P. Cachon, "The allocation of inventory risk in a supply chain: push, pull, and advance-purchase discount contracts," Management Science, vol. 50, no. 2, pp. 222-238, 2004.

[23] T. M. Choi, N. Liu, S. Ren, and C. Hui, "No refund or full refund: when should a fashion brand offer full refund consumer return service for mass customization products?" Mathematical Problems in Engineering, vol. 2013, Article ID 561846, 14 pages, 2013.

[24] C. Chiu, T. M. Choi, H. Yeung, and Y. Zhao, "Sales rebate contracts in fashion supply chains," Mathematical Problems in Engineering, vol. 2012, Article ID 908408, 19 pages, 2012.

[25] H. J. Peng and M. H. Zhou, "Quantity discount supply chain models with fashion products and uncertain yields," Mathematical Problems in Engineering, vol. 2013, Article ID 895784, 11 pages, 2013.

[26] J. H. Zheng, B. Shen, P. S. Chow, and C. Chiu, "The impact of the strategic advertising on luxury fashion brands with social influences," Mathematical Problems in Engineering, vol. 2013, Article ID 534605, 16 pages, 2013.

[27] P. S. Chow, Y. L. Wang, T. M. Choi, and B. Shen, "An experimental study on the effects of minimum profit share on supply chains with markdown contract: risk and profit analysis, forthcoming in the omega," The International Journal of Management Science, 2014.

[28] Y. He, Z. Liu, and K. Usman, "Coordination of cooperative advertising in a two-period fashion and textiles supply chain," Mathematical Problems in Engineering, vol. 2014, Article ID 356726, 10 pages, 2014.

[29] M. Yu, R. Yang, and L. Ma, "The quota-based compensation plan in fashion retailing industry under asymmetric information," Mathematical Problems in Engineering, vol. 2014, Article ID 263419, 11 pages, 2014.

[30] M. Liu, W. Bi, X. Chen, and G. Li, "Dynamic pricing of fashionlike multiproducts with customers' reference effect and limited memory," Mathematical Problems in Engineering, vol. 2014, Article ID 157865, 10 pages, 2014.

[31] J. Nie, Z. Huang, Y. Zhao, and Y. Shi, "Collective recycling responsibility in closed-loop fashion supply chains with a third party: financial sharing or physical sharing?" Mathematical Problems in Engineering, vol. 2013, Article ID 176130, 11 pages, 2013.

[32] B. Shen, J. H. Zheng, P. S. Chow, and K. Y. Chow, "Perception of fashion sustainability in online community," Journal of the Textile Institute, 2014.

[33] C. Dong, B. Shen, P. S. Chow, L. Yang, and C. T. Ng, "Sustainability investment under cap-and-trade regulation," Annals of Operations Research, 2014.

[34] W. K. Yeung, T. M. Choi, and T. C. E. Cheng, "Optimal scheduling of a single-supplier single-manufacturer supply chain with common due windows," IEEE Transactions on Automatic Control, vol. 55, no. 12, pp. 2767-2777, 2010. 


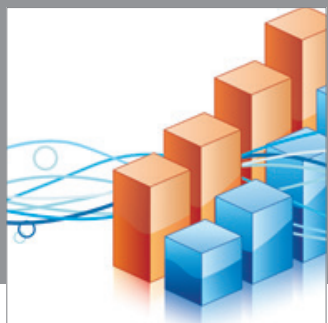

Advances in

Operations Research

mansans

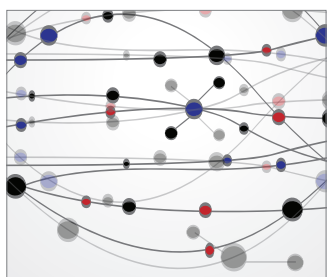

The Scientific World Journal
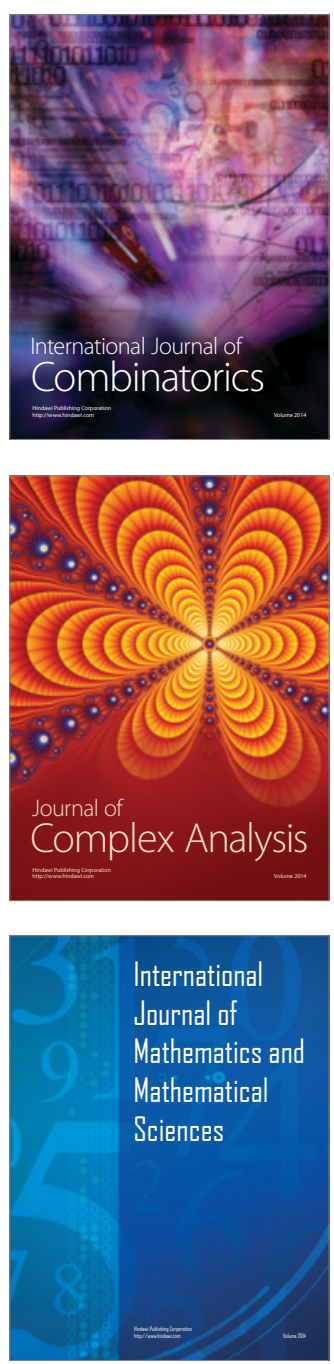
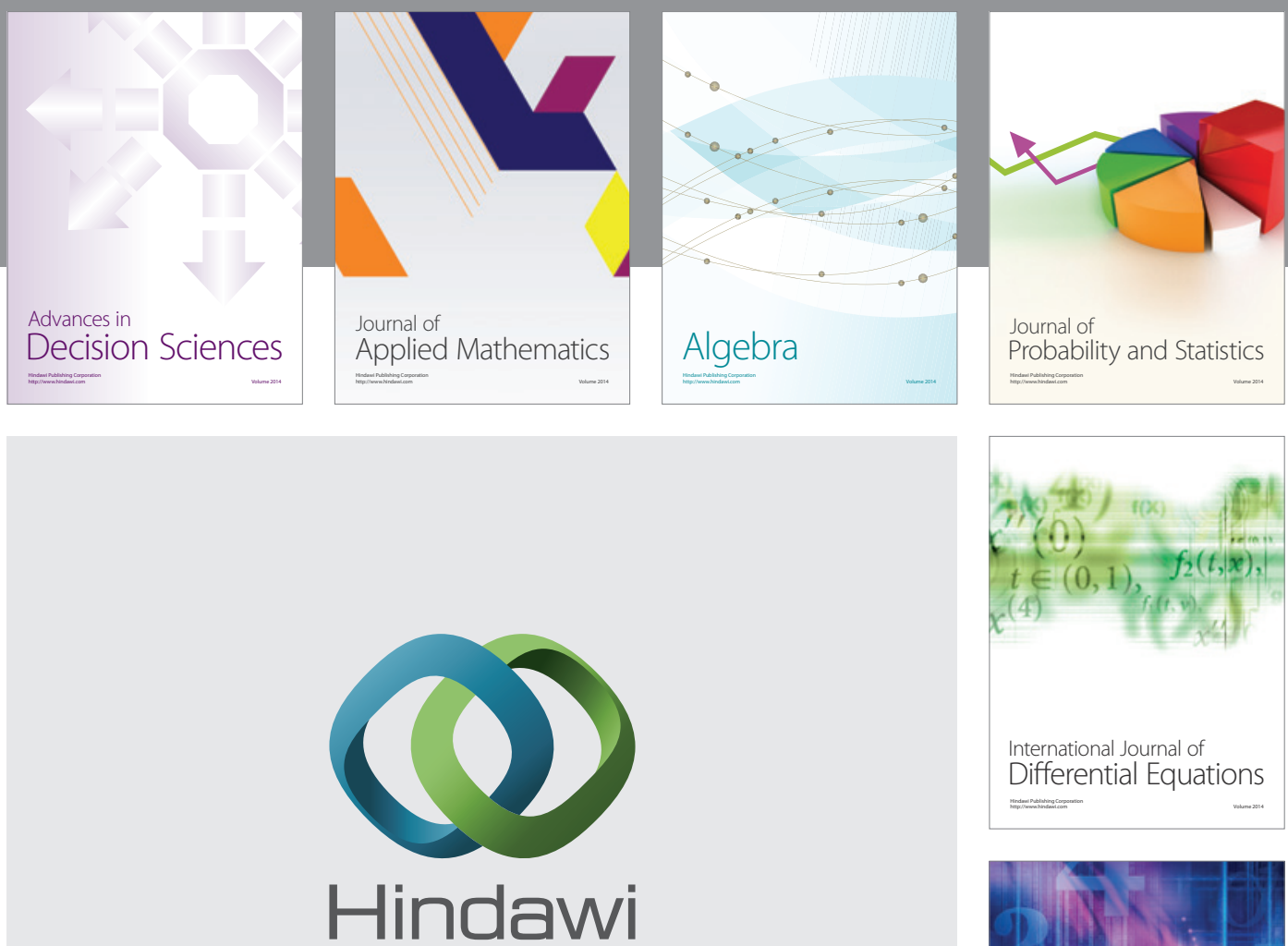

Submit your manuscripts at http://www.hindawi.com
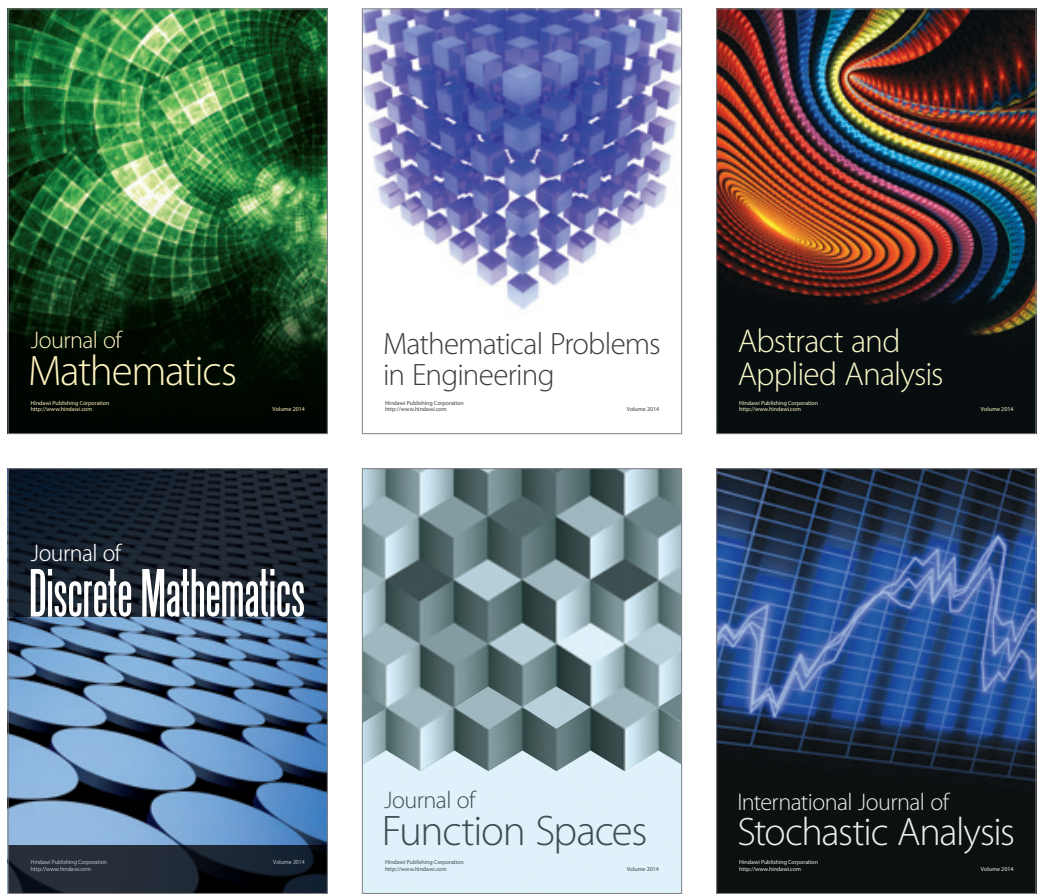

Journal of

Function Spaces

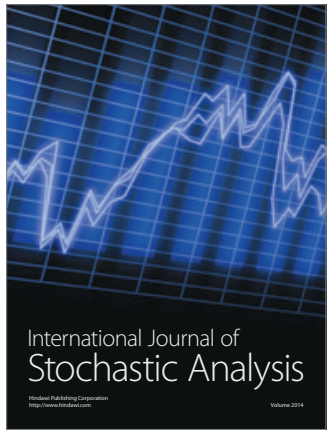

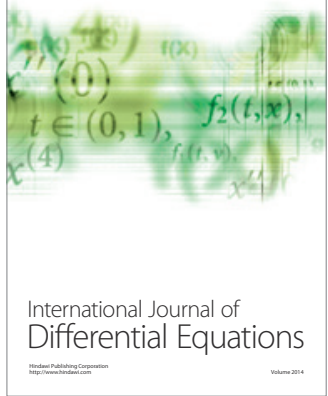
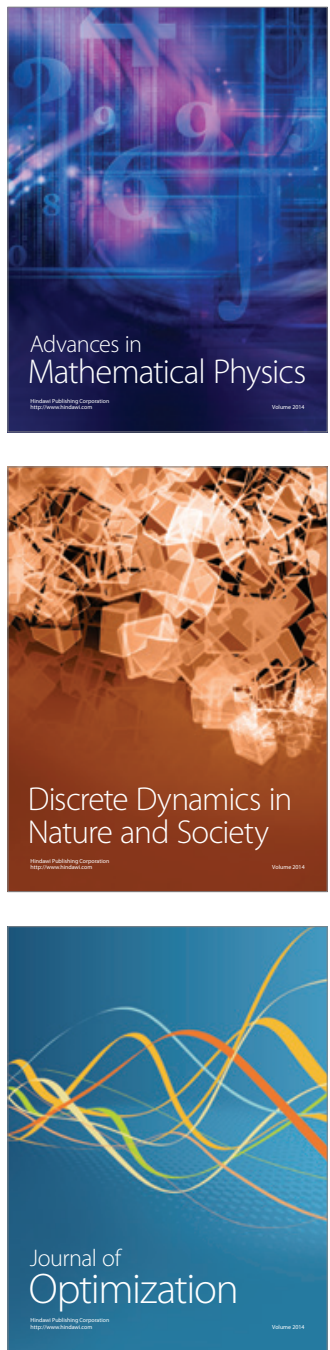